\title{
MAMMOGRAM IMAGE SEGMENTATION USING ROUGH CLUSTERING
}

\author{
R. Subash Chandra Boss ${ }^{1}$, K. Thangavel ${ }^{2}$, D. Arul Pon Daniel ${ }^{3}$ \\ ${ }^{1,2,3}$ Department of Computer Science, Periyar University, Salem-636 011, Tamilnadu, India \\ rmsubash_18@yahoo.co.in,drktvelu@yahoo.com,apdaniel86@yahoo.com
}

\begin{abstract}
The mammography is the most effective procedure to diagnosis the breast cancer at an early stage. This paper proposes mammogram image segmentation using Rough K-Means (RKM) clustering algorithm. The median filter is used for pre-processing of image and it is normally used to reduce noise in an image. The 14 Haralick features are extracted from mammogram image using Gray Level Cooccurrence Matrix (GLCM) for different angles. The features are clustered by K-Means, Fuzzy C-Means (FCM) and Rough K-Means algorithms to segment the region of interests for classification. The result of the segmentation algorithms compared and analyzed using Mean Square Error (MSE) and Root Means Square Error (RMSE). It is observed that the proposed method produces better results that the existing methods.
\end{abstract}

Keywords- Mammogram, Data mining, Image Processing, Feature Extraction, Rough $K$ - Means and Image Segmentation

\section{INTRODUCTION}

Breast cancer is the most common type of cancer found among women. It is the most frequent form of cancer and one in 22 women in India is likely to suffer from breast cancer [1]. This is the second main cause of cancer death in women. Breast cancer in India is in rise and rapidly becoming the leading cancer in females and death toll is increasing at fast rate and no effective way to treat this disease yet. So, early detection becomes a critical factor to cure the disease and improving the surviving rate. Generally the X-ray mammography is a valuable and most reliable method in early detection.

Image segmentation refers to the process of partitioning a digital image to multiple segments or set of pixels. The goal of segmentation is to simplify the representation of an image into different segments that is more meaningful and easier to analyze. Image segmentation is typically used to locate objects and boundaries in images. It is also the process of assigning a label to every pixel in an image such that pixels with the same label share certain visual characteristics. The result of image segmentation is a set of segments that collectively cover the entire image. Image segmentation is nothing but the process of dividing an image into disjoint homogenous regions [2]. These regions usually contain similar objects of interest. The homogeneity of the segmented regions can be measured using pixel intensity. Image segmentation techniques can be broadly classified as into five main classes threshold based, Cluster based, Edge based, Region based, and Watershed based segmentation [3]. This paper focuses on cluster based segmentation.
Data mining of medical images is used to collect effective models, relations, rules, abnormalities and patterns from large volume of data [4]. This procedure can accelerate the diagnosis process and decision making. Different methods of data mining have been used to detect and classify anomalies in mammogram images such as K- means, FCM, wavelets, ant colony optimization and neural network.

Clustering is defined as the optimal partitioning of a given set of $\mathrm{n}$ data points into specified number of subgroups, such that data points belonging to the same group are as similar to each other as possible [5]. The data points from two different groups share the maximum difference. Image segmentation is also considered as a clustering problem where the features describing each pixel correspond to a pattern, and each image region corresponds to a cluster. Some hard clustering approaches do not consider overlapping of classes which occur in many practical image segmentation problems.

K-Means clustering generate a specific number of disjoints and flat (non-hierarchical) clusters. It is well suited to generate globular clusters. The K-Means method is numerical, unsupervised, non-deterministic and iterative. Some of disadvantages in K-Means algorithm are difficult in comparing quality of the clusters produced (e.g. for different initial partitions or values of $\mathrm{K}$ affect outcome), Fixed number of clusters can make it difficult to predict what $\mathrm{K}$ should be, does not work well with non-globular clusters. Different initial partitions can result in different final clusters [6]. 
There are several methods for segmenting images based on two fundamental properties of the pixel values: One of them is "discontinuity" that uses the discontinuities between gray-level regions to detect isolated points, edges and contours within an image. The other is "similarity" that uses decision criteria to separate an image into different group based on the similarity of the pixel levels. Clustering is one of the methods of second category. Clustering algorithms attempt to separate a dataset into distinct regions of membership. Fuzziness occurs due to the presence of pixels and use of fuzzy methods makes the results more reliable. Integration of these two techniques (C-Means clustering \& Fuzzy methods) leads to Fuzzy C-Means clustering (FCM) that consider each cluster as a fuzzy set. Computational steps of FCM algorithm are: choosing the number of classes and the initial value for the means, classify the image by defining membership value for each class and assigning the pixels to the class corresponding to the closest mean, Re-computing the means of the class and at last, if the change in any of the means is more than some pre-defined small positive value, then stopping, else reclassifying the image based on membership functions and iterating the algorithm.

This paper is organized as follows: Section 2 discusses the Rough set theory. Section 3 discusses the Image as a rough set. Section 4 discusses the Rough set in medical image segmentation. Section 5 describes the Pre-processing work. Section 6 discusses the Feature Extraction techniques. Section 7 explains the Clustering algorithms. Section 8 discusses experimental results and Section 9 covers conclusion.

\section{ROUGH SET THEORY}

Rough set theory $[7,8]$ is a fairly recent intelligent technique for managing uncertainty that is used for the discovery of data dependencies, to evaluate the importance of attributes, to discover patterns in data, to reduce redundancies, and to recognize and classify objects. Moreover, it is being used for the extraction of rules from databases where one advantage is the creation of readable if-then rules. Such rules have the potential to reveal previously undiscovered patterns in the data; furthermore, it also collectively functions as a classifier for unseen samples. Unlike other computational intelligence techniques, rough set analysis requires no external parameters and uses only the information presented in the given data. One of the useful features of rough set theory is that it can tell whether the data is complete or not based on the data itself. If the data is incomplete, it will suggest that more information about the objects is required. On the other hand, if the data is complete, rough sets are able to determine whether there are any redundancies and find the minimum data needed for classification. This property of rough sets is very important for applications where domain knowledge is very limited or data collection is expensive because it makes sure the data collected is just sufficient to build a good classification model without sacrificing accuracy $[7,8]$.
In rough set theory, sample objects of interest are usually represented by a table called an information table. Rows of an information table correspond to objects and columns correspond to object features. For a given set B of functions representing object features and a set of sample objects $X$, an indiscernibility relation $\square \mathrm{B}$ is a set of pairs ( $\left.\mathrm{x}, \mathrm{x}^{\prime} \quad\right) \in \mathrm{X} \times \mathrm{X}$ such that $\mathrm{f}(\mathrm{x})=\mathrm{f}$ $\left(\mathrm{X}^{\prime}\right)$ for all $\mathrm{f} \in \mathrm{B}$. The relation $\sim \mathrm{B}$ defines a quotient set $\mathrm{X} /$ $\sim$ B, i.e., a set of all classes in the partition of $X$ defined by $\sim B$. Rough set theory identifies three approximation regions defined relative to $\mathrm{X} / \sim \mathrm{B}$, namely, lower approximation, upper approximation and boundary. The lower approximation of a set $\mathrm{X}$ contains all classes that are subsets of $\mathrm{X}$, the upper approximation contains all classes with non-empty intersections with $\mathrm{X}$, and the boundary is the set difference between the upper and lower approximations.

Rough image processing can be defined as the collection of approaches and techniques that understand represent and process images, their segments and features as rough sets [9]. In images boundaries between object regions are often ill-defined [10]. This uncertainty can be handled by describing the different objects as rough sets with upper (or outer) and lower (or inner) approximations.

\section{IMAGE AS A ROUGH SET}

In gray scale images boundaries between object regions are often ill defined because of grayness and / or spatial ambiguities [11]. Here, the concepts of upper and lower approximation can be viewed, as outer and inner approximations of an image region in terms of granules respectively.

Let the universe $U$ be an image consisting of a collection of pixels. Then if we partition $U$ into a collection of nonoverlapping windows (of size $\mathrm{m} \times \mathrm{n}$, say), each window can be considered as a granule G. In other words, the induced equivalence classes $\operatorname{Im} \times \mathrm{n}$ have $\mathrm{m} \times \mathrm{n}$ pixels in each non-overlapping window. Given this granulation, object regions in the image can be approximated by rough sets.

Let us consider an object-background separation (a two class) problem of an $\mathrm{M} \times \mathrm{N}$, L level image. Let $\operatorname{prop}(\mathrm{B})$ and $\operatorname{prop}(\mathrm{O})$ represent two properties (say, gray level intervals $0,1, \ldots, \mathrm{T}$ and $\mathrm{T}+1, \mathrm{~T}+2, \ldots, \mathrm{L}-1)$ that characterize back-ground and object can be viewed as two sets with their rough representation as follows:

The inner approximation of the object $\left(\underline{\mathrm{O}}_{\mathrm{r}}\right)$ :

$$
\underline{\mathrm{O}}_{\mathrm{r}}=\left\{\bigcup_{\mathrm{i}} \mathrm{G}_{\mathrm{i}} \mid \mathrm{P}_{\mathrm{j}}>\mathrm{T}, \forall \mathrm{j}=1,2,3, \ldots, \mathrm{m}^{*} \mathrm{n}\right\} \text {. }
$$

Outer approximation of the object $\left(\underline{\mathrm{O}}_{\mathrm{r}}\right)$ :

$$
\overline{\mathrm{O}}_{\mathrm{T}}=\left\{\bigcup_{\mathrm{i}} \mathrm{G}_{\mathrm{i}} \exists_{\mathrm{j}}, \mathrm{j}=1,2,3, \ldots, \mathrm{m} * \text { n, s.t } \mathrm{P}_{\mathrm{j}}>\mathrm{T}\right\} \text {. }
$$


Inner approximation of the background $\left(\underline{B}_{\mathrm{T}}\right)$ :

$$
\underline{\mathrm{B}}_{\mathrm{T}}=\left\{\bigcup_{\mathrm{i}} \mathrm{G}_{\mathrm{i}} \mid \mathrm{P}_{\mathrm{j}} \leq \mathrm{T}, \forall \mathrm{j}=1,2,3, . ., \mathrm{m} * \mathrm{n}\right\} \text {. }
$$

Outer approximation of the background $\left(\underline{B}_{T}\right)$ :

$$
\underline{B}_{\mathrm{T}}=\left\{\bigcup_{\mathrm{i}} \mathrm{G}_{\mathrm{i}} \exists \mathrm{j}, \mathrm{j}=1,2,3, . ., \mathrm{m} * \text { n s.t. } \mathrm{P}_{\mathrm{j}} \leq \mathrm{T}\right\}
$$

Therefore, the rough set representation of the image (i.e., object $\mathrm{O}_{\mathrm{T}}$ and background $\mathrm{B}_{\mathrm{T}}$ ) for a given $\mathrm{I}_{\mathrm{m} \times \mathrm{n}}$ depends on the value of $\mathrm{T}$. Let the roughness of object $\mathrm{O}_{\mathrm{T}}$ and background $\mathrm{B}_{\mathrm{T}}$ be defined as

$$
\begin{aligned}
& \mathrm{R}_{\mathrm{O}_{\mathrm{T}}}=1-\frac{\left|\underline{\mathrm{O}}_{\mathrm{T}}\right|}{\left|\overline{\mathrm{O}}_{\mathrm{T}}\right|}=\frac{\left|\overline{\mathrm{O}}_{\mathrm{T}}\right|-\left|\underline{\mathrm{O}}_{\mathrm{T}}\right|}{\left|\overline{\mathrm{O}}_{\mathrm{T}}\right|} \\
& \mathrm{R}_{\mathrm{B}_{\mathrm{T}}}=1-\frac{\left|\underline{\mathrm{B}}_{\mathrm{T}}\right|}{\left|\overline{\mathrm{B}}_{\mathrm{T}}\right|}=\frac{\left|\overline{\mathrm{B}}_{\mathrm{T}}\right|-\left|\underline{\mathrm{B}}_{\mathrm{T}}\right|}{\left|\overline{\mathrm{B}}_{\mathrm{T}}\right|},
\end{aligned}
$$

Where $\left|\underline{\mathrm{O}}_{\mathrm{T}}\right|$ and $\left|\overline{\mathrm{O}}_{\mathrm{T}}\right|$ are the cardinality of the sets $\underline{\mathrm{O}}_{\mathrm{T}}$ and $\overline{\mathrm{O}}_{\mathrm{T}}$, and $\left|\underline{\mathrm{B}}_{\mathrm{T}}\right|$ and $\left|\overline{\mathrm{B}}_{\mathrm{T}}\right|$ are the cardinality of the sets $\underline{\mathrm{B}}_{\mathrm{T}}$ and $\overline{\mathrm{B}}_{\mathrm{T}}$, respectively.

\section{ROUGH SETS IN MEDICAL IMAGE SEGMENTATION}

One of the most important tasks in medical imaging is segmentation as it is often a pre-cursor to subsequent analysis, whether manual or automated. The basic idea behind segmentation-based rough sets is that while some cases may be clearly labeled as being in a set $\mathrm{X}$ (called positive region in rough sets theory), and some cases may be clearly labelled as not being in $\mathrm{X}$ (called negative region), limited information prevents us from labeling all possible cases clearly. The remaining cases cannot be distinguished and lie in what is known as the boundary region. Kobashi et al. [12] introduced rough sets to treat nominal data based on concepts of categorization and approximation for medical image segmentation. The proposed clustering method extracts features of each pixel by using thresholding and labeling algorithms. Thus, the features are given by nominal data. The ability of the proposed method was evaluated by applying it to human brain MRI images. Peters et al. [13] presented a new form of indiscernibility relation based on k-means clustering of pixel values. The end result is a partitioning of a set of pixel values into bins that represent equivalence classes. The proposed approach allows introducing a form of upper and lower approximation specialized relative to sets of pixel values.
An improved clustering algorithm based on rough sets and entropy theory was presented by Chena and Wang [14]. The method avoids the need to pre-specify the number of clusters which is a common problem in clustering based segmentation approaches. Clustering can be performed in both numerical and nominal feature spaces with a similarity introduced to replace the distance index. At the same time, rough sets are used to enhance the algorithm with the capability to deal with vagueness and uncertainty in data analysis. Shannon's entropy was used to refine the clustering results by assigning relative weights to the set of features according to the mutual entropy values. A novel measure of clustering quality was also presented to evaluate the clusters. The experimental results confirm that both efficiency and clustering quality of this algorithm are improved

An interesting strategy for colour image segmentation using rough sets has been presented by Mohabey et al. [15]. They introduced a concept of encrustation of the histogram, called his ton, for the visualization of multi-dimensional colour information in an integrated fashion and study its applicability in boundary region analysis. The his ton correlates with the upper approximation of a set such that all elements belonging to this set are classified as possibly belonging to the same segment or segments showing similar colour value. The proposed encrustation provides a direct means of separating a pool of inhomogeneous regions into its components. This approach can then be extended to build a hybrid rough set theoretic approximations with fuzzy c-means based colour image segmentation. The technique extracts colour information regarding the number of segments and the segment centers of the image through rough set theoretic approximations which then serve as the input to a fuzzy c-means algorithm.

Widz et al. [16] introduced an automated multi-spectral MRI segmentation technique based on approximate reducts derived from the theory of rough sets. They utilised T1, T2 and PD MRI images from a simulated brain database as a gold standard to train and test their segmentation algorithm. The results suggest that approximate reducts, used alone or in combination with other classification methods, may provide a novel and efficient approach to the segmentation of volumetric MRI data sets. Segmentation accuracy reaches $96 \%$ for the highest resolution images and $89 \%$ for the noisiest image volume. They tested the resultant classifier on real clinical data, which yielded an accuracy of approximately $84 \%$.

\section{PRE-PROCESSING}

Pre-processing is an important issue in low-level image processing. It is possible to filter out the noise present in image using filtering. A high pass filter passes the frequent changes in the gray level and a low pass filter reduces the frequent changes in the gray level of an image. That is; the low pass filter smoothes and often removes the sharp edges. A special type of low pass filter is the Median filter. The Median 
filter takes an area of image ( $3 \times 3,5 \times 5,7 \times 7$ etc), observes all pixel values in that area and puts it into the array called element array. Then, the element array is sorted and the median value of the element array is found out. We have achieved this by sorting the element array in the ascending order using bubble sort and returning the middle elements of the sorted array as the median value. The output image array is the set of all the median values of the element arrays obtained for all the pixels. Median filter goes into a series of loops which cover the entire image array [13].

Some of the important features of the Median filter are: It is a non-linear digital filtering technique. It works on a monochrome color image. It reduces "speckle" and "salt and paper" noise. It is easy to change the size of the Median filter. It removes noise in image, but adds small changes in noise-free parts of image. It does not require convolution. Its edge preserving nature makes it useful in many cases.

The selected median value will be exactly equal to one of the existing brightness value, so that no round-off error is involved when we take independently with integer brightness values comparing to the other filters $[13,14]$.

\section{FEATURE EXTRACTION}

The idea is to calculate the co-occurrence matrix for small regions of the image and then use this matrix to find statistic values, for instance Contrast, Correlation, Uniformity, Homogeneity, Probability, Inverse and Entropy. The distance and angle is converted to a vertical and a horizontal offset in pixels according to the following list of angle offset.

Gray-Level Co-occurrence Matrix (GLCM) is one of the texture descriptors most used in the literature. Starting to summarize different researches we can find works by Bovis and Singh [19] studying how to detect masses in mammograms on the basis of textural features using five co-occurrence matrices statistics extracted from four spatial orientations, horizontal, left diagonal, vertical and right diagonal corresponding to $(00,450,900$ and $1350)$ and four pixel distance ( $\mathrm{d}=1,3,6$ and 9). Hence, a classification is performed using each feature vector and linear discriminate analysis. According to Marti et al. [20], GLCMs are frequently used in computer vision obtaining satisfactory results as texture classifiers in different applications. Their approach uses mutual information with the purpose to calculate the amount of mutual information between images using histograms distributions obtained by grey-level co-occurrence matrices. Blot and Zwiggelaar [21, 22] proposed two approaches based in detection and enhancement of structures in images using GLCM. The purpose is to compare the difference between these two matrices obtaining a probability estimate of the abnormal image structures in the ROI. Finally, another study based on background texture extraction for classification of Blot and Zwiggelaar [23] presented their work where there is a statistical difference between GLCM for image regions that include image structures and regions that only contain background texture which is provided by a classification in mammograms. In 2003, different approaches based on cooccurrences matrix as a feature descriptors extraction were developed. Houssay et al. [24] presented a neuro-fuzzy model for fast detection of candidate circumscribed masses in mammograms and texture features are estimated using cooccurrence matrices which are used to train the neuro-fuzzy model. On the other hand, Marti et al. [25] proposed a supervised method for the segmentation of masses in mammographic images using texture features which present a homogeneous behaviour inside the selected region.

Jirari [26] proposes an intelligent Computer-Aided Detection system (CAD) by constructing five co-occurrence matrices at different distances for each suspicious region. A different number of statistical features are used to train and test the Radial Basis neural network. Another work is presented by Lena et al. [27] with the study of a multi-resolution texture feature of second order statistics were extracted from spatial GLCM using different orientations and distances.

Recent studies, Karahaliou et al. [28] investigate whether texture properties of the tissue surrounding micro-calcifications using a wavelet transform. Thirteen textural features were calculated from four GLCMs. Finally, Lyra et al. [29] study how to identify breast tissue quality data quantification using a CAD system, where images categorized using the BIRADS breast density index. The texture features were derived for each subregion from an averaged gray- level co-occurrence matrix (GLCM). Karahaliou et al. [30] Gray-level texture and wavelet coefficient texture features at three decomposition levels are extracted from surrounding tissue regions of interest.

\subsection{Grey-Level Co-Occurrence Matrices:}

The Statistics of grey-level histograms give parameters for each processed region but do not provide any information about the repeating nature of texture. According to Beichel and Sonka [31], the occurrence of gray-level configuration may be described by matrices of relative frequencies, called cooccurrence matrices. Hence, the GLCM is a tabulation of how often different combinations of pixel brightness values (grey levels) occur in an image. GLCM are constructed by observing pairs of image cells distance $d$ from each other and incrementing the matrix position corresponding to the grey level of both cells. This allows us to derive four matrices for each given distance: 0 , $\mathrm{P}(450, \mathrm{~d}), \mathrm{P}(900, \mathrm{~d})$, and $\mathrm{P}(1350, \mathrm{~d})$. For instance, $\mathrm{P}(00$; d) is defined as follows:

$$
\begin{gathered}
\mathrm{P}\left(\left(0^{0}\right), \mathrm{d}(\mathrm{a}, \mathrm{b})\right)=\mid\{((\mathrm{k}, \mathrm{l}),(\mathrm{m}, \mathrm{n})) \in \mathrm{D}: \\
\mathrm{k}-\mathrm{m}=0,|\mathrm{l}-\mathrm{n}|=\mathrm{d}, \mathrm{f}(\mathrm{k}, \mathrm{l})=\mathrm{a}, \mathrm{f}(\mathrm{m}, \mathrm{n})=\mathrm{b}\} \mid
\end{gathered}
$$

Where each $P$ value is the number of times that: $f\left(x_{1}, y_{1}\right)=i$, $\mathrm{f}\left(\mathrm{x}_{2}, \mathrm{y}_{2}\right)=\mathrm{j},\left|\mathrm{x}_{1}-\mathrm{x}_{2}\right|=\mathrm{d}$ and $\mathrm{y} 1=\mathrm{y} 2$ append simultaneously in 
the image. $\mathrm{P}\left(45^{\circ}, \mathrm{d}\right), \mathrm{P}\left(90^{\circ}, \mathrm{d}\right), \mathrm{P}\left(135^{\circ}, \mathrm{d}\right)$ are defined similarly:

$$
\begin{aligned}
& \mathrm{P}\left(\left(45^{0}\right), \mathrm{d}(\mathrm{a}, \mathrm{b})\right)=\mid \mathrm{f}((\mathrm{k}, \mathrm{l}) ;(\mathrm{m}, \mathrm{n})) \in \mathrm{D}: \\
& (\mathrm{k}-\mathrm{m}=\mathrm{d}, \mathrm{l}-\mathrm{n}=-\mathrm{d}) \text { OR }(\mathrm{k}-\mathrm{m}=\mathrm{d} ; \mathrm{l}-\mathrm{n}=\mathrm{d}), \quad \mathrm{f}(\mathrm{k}, \mathrm{l})=\mathrm{a}, \\
& \mathrm{f}(\mathrm{m}, \mathrm{n})=\mathrm{b}\} \mid \\
& \mathrm{P}\left(\left(90^{0}\right), \mathrm{d}(\mathrm{a}, \mathrm{b})\right)=\mid\{((\mathrm{k}, \mathrm{l}),(\mathrm{m}, \mathrm{n})) \in \mathrm{D}: \\
& |\mathrm{k}-\mathrm{m}|=\mathrm{d}, \mathrm{l}-\mathrm{n}=0, \mathrm{f}(\mathrm{k}, \mathrm{l})=\mathrm{a}, \mathrm{f}(\mathrm{m}, \mathrm{n})=\mathrm{b}\} \mid \\
& \mathrm{P}\left(\left(135^{0}\right), \mathrm{d}(\mathrm{a}, \mathrm{b})\right)=\mid \mathrm{f}((\mathrm{k}, \mathrm{l}) ;(\mathrm{m}, \mathrm{n})) \in \mathrm{D}: \\
& (\mathrm{k}-\mathrm{m}=\mathrm{d}, \mathrm{l}-\mathrm{n}=\mathrm{d}) \text { OR }(\mathrm{k}-\mathrm{m}=-\mathrm{d}, \mathrm{l}-\mathrm{n}=-\mathrm{d}), \mathrm{f}(\mathrm{k}, \mathrm{l})=\mathrm{a}, \mathrm{f} \\
& (\mathrm{m}, \mathrm{n})=\mathrm{b}\} \mid
\end{aligned}
$$

A co-occurrence matrix contains the frequency of a certain pair of pixels repetition in an image. According to the previous formulas the parameters needed are the follows:

Number of grey levels: Normally, it is used a grayscale image of 256 grey levels, which means a high computational cost because all possible pixel pairs must be taken into account. The solution is to generate the matrix reducing the number of grayscales, and so the number of possible pixel combinations. The cooccurrence matrix is always square with the same dimensionality as the number of grey-levels chosen.

Distance between pixels (d): the co-occurrence matrix stores the number of times that a certain pair of pixels is found in the image. Normally the pair of pixels are just neighbors, but the matrix could also be computed analyzing the relation between non consecutive pixels. Thus a distance between pixels must be previously defined.

Angle $(\theta)$ : Similarly to the distance it is necessary to define the direction of the pair of pixels. The most common directions are 00, 450, 900, 1350 and its symmetric equivalents. Figure 1 shows an example of how we can construct a co-occurrence matrix with eight grey levels, computed using one for distance between pixels and zero degrees for the direction. In this case, the element $(1,1)$ of $\mathrm{C}$ matrix is equivalent to 1 because it has been found only one occurrence in the original image f. Another example is shown in the Figure 1 . On the element $(6,2)$, where there are three occurrences because a pixel with a value of 6 has a pixel valued 2 immediately to its right. The other elements of $\mathrm{C}$ are computed in the same way.

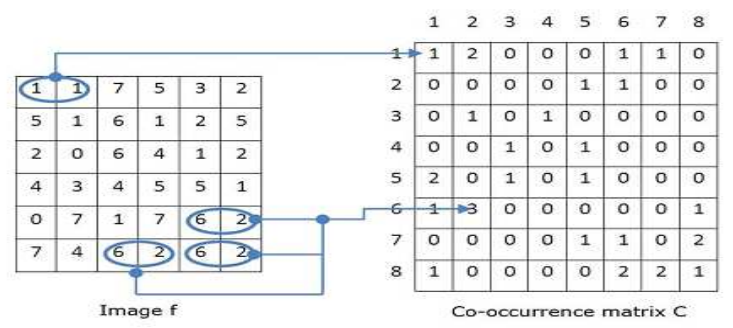

Figure1. How to generate a co-occurrence matrix
The co-occurrence matrix has some properties about the spatial distribution of the gray levels in the texture image. Haralick [31] proposed descriptors used for characterizing co-occurrence matrices of size $\mathrm{K} \times \mathrm{K}$. The term $\mathrm{Pij}$ is the ijth term of $\mathrm{C}$ divided by the sum of the elements $\mathrm{C}$.

\section{CLUSTERING ALGORITHM}

The main objective in cluster analysis is to group objects that are similar in one cluster and separate objects that are dissimilar by assigning them to different clusters. One of the most popular clustering methods is K-Means clustering algorithm. It classifies object to a pre-defined number of clusters, which is given by the user (assume $\mathrm{K}$ clusters). The idea is to choose random cluster centres, one for each cluster. These centres are preferred to be as far as possible from each other. In this algorithm mostly Euclidean distance is used to find distance between data points and centroids [7]. The Euclidean distance between two multidimensional data points $\mathrm{X}=(\mathrm{x} 1, \mathrm{x} 2, \mathrm{x} 3, \ldots, \mathrm{xm})$ and $\mathrm{Y}=(\mathrm{y} 1$, $\mathrm{y} 2, \mathrm{y} 3, \ldots, \mathrm{ym})$ is described as follows:

$$
D(X, Y)=\sqrt{\sum_{i=0}^{n}\left(x_{i}-y_{j}\right)^{2}}
$$

The K-Means method aims to minimize the sum of squared distances between all points and the cluster centre. This procedure consists of the following steps, as described below.

\subsection{K-Means Algorithm:}

Require: $D=\left\{d_{1}, d_{2}, d_{3}, \ldots, d_{n}\right\} / /$ Set of $\mathrm{n}$ data points. $K$ - Number of desired clusters

Ensure: $A$ set of $K$ clusters.

Steps-1: Arbitrarily choose $k$ data points from $D$ as initial centroids;

Steps-2: Repeat: Assign each point $d_{i}$ to the cluster which has the closest centroid;

Calculate the new mean for each cluster;

Steps-3: Until convergence criteria is met.

Though the K-Means algorithm is simple, it has some drawbacks of quality of the final clustering, since it highly depends on the arbitrary selection of the initial centroids. Data clustering is the process of dividing data elements into classes or clusters so that items in the same class are as similar as possible, and items in different classes are as dissimilar as possible. Depending on the nature of the data and the purpose for which clustering is being used, different measures of similarity may be used to place items into classes, where the similarity measure controls how the clusters are formed. Some examples of measures that can be used as in clustering include distance, connectivity, and intensity. 
In hard clustering, data is divided into distinct clusters, where each data element belongs to exactly one cluster. In fuzzy clustering (also referred to as soft clustering), data elements can belong to more than one cluster, and associated with each element is a set of membership levels. These indicate the strength of the association between that data element and a particular cluster. Fuzzy clustering is a process of assigning these membership levels, and then using them to assign data elements to one or more clusters.

\subsection{Fuzzy C-Means Algorithm}

Input: Dataset $X$ of $n$ objects with $d$ features, value of $K$ and fuzzification value $m>1$

Output: Membership matrix $U_{i j}$ for $n$ objects and $K$ clusters

\section{Procedure:}

Step-1: Declare a membership matrix $U$ of size $n \times K$.

Step-2: Generate $K$ cluster centroids randomly within the range of the data or select $K$ objects randomly as initial cluster centroids. Let the centroids be $\mathrm{c}_{1}, c_{2}, \ldots, c_{K}$.

Step-3: Calculate the distance measure $d_{i j}=\left\|x_{i}-c_{j}\right\|$ using Euclidean distance, for all cluster centroids $c_{j}, j=1,2, \ldots, K \quad$ and data objects $x_{i}, i=1,2, \ldots, n$.

Step-4: Compute the Fuzzy membership matrix $U_{i j}$

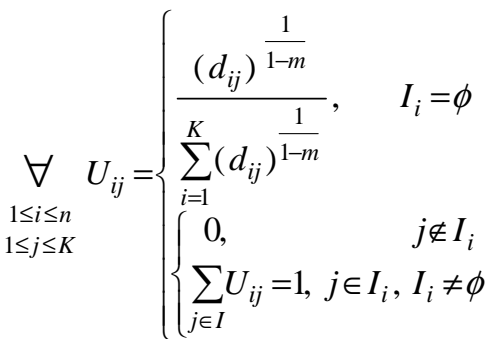

$$
\begin{aligned}
& \text { where } \underset{\forall 1 \leq i \leq n}{I_{i}}=\left\{j \mid 1 \leq j \leq K ; d_{i j}=0\right\}
\end{aligned}
$$

Step-5: Compute new cluster centroids $c_{j}$

$$
1 \leq{ }_{j \leq K} \quad c_{j}=\frac{\sum_{i=1}^{n}\left(U_{i j}\right)^{m} x_{i}}{\sum_{i=1}^{n}\left(U_{i j}\right)^{m}}
$$

Step-6: Repeat steps 3 to 5 until convergence.

\subsection{Rough K-Means Clustering}

- Lingras proposed Rough K-Means (RKM) algorithm by incorporating rough sets into K-Means algorithm

- RKM algorithm does not verify all the properties of rough set theory, but uses the following basic properties:

Property-1: a data object can be a member of one lower approximation at most.

Property-2: a data object that is a member of the lower approximation of a cluster is also member of the upper approximation of the same cluster.

Property-3: a data object that does not belong to any lower approximation is a member of at least two upper approximations.

- According to the above three properties, the lower approximation is a subset of the upper approximation

The difference between upper and lower approximation is called boundary region, which contains objects in multiple clusters

- The membership of each object in lower and upper approximation is determined by three parameters $W_{l}$, $W_{u}$ and $\varepsilon$

- The parameters $W_{l}$ and $W_{u}$ correspond to the relative importance of lower and upper bounds, and $W_{l}+W_{u}=$ 1

- The $\varepsilon$ is a threshold parameter used to control the size of boundary region

Input: Dataset of $\mathrm{n}$ objects with $\mathrm{d}$ features, number of clusters $\mathrm{K}$ and values of parameters Wlower, Wupper, and epsilon.

Output: Lower approximation $\underline{U}(\mathrm{~K})$ and Upper approximation $\underline{U}(K)$ of $\mathrm{K}$ Clusters.

\section{Procedure:}

Step1: Randomly assign each data object one lower approximation $\underline{U}(\mathrm{~K})$. By property 2 , the data object also belongs to upper approximation $\underline{U}(K)$ of the same Cluster.

Step 2: Compute Cluster Centroids $\mathrm{Cj}$

$$
\text { If } \begin{aligned}
& \underline{U}(K) \neq \phi \text { and } \bar{U}(K)-\underline{U}(K)=\phi \\
& C_{j}=\frac{\sum_{x \varepsilon \underline{U}(K)} x j}{\underline{U}(K)}
\end{aligned}
$$

Else

$$
\text { If } \underline{U}(K) \neq \phi \text { and } \bar{U}(K)-\underline{U}(K)=\phi
$$




$$
C_{j}=\frac{\sum_{x \varepsilon(\bar{U}(K)-\underline{U}(K))} x_{j}}{|\bar{U}(K)-\underline{U}(K)|}
$$

Else

$$
C_{j}=W_{l} \times \frac{\sum_{x \varepsilon \underline{U}(K)} x_{j}}{\underline{U}(K)}+W_{u} \times \frac{\sum_{x \varepsilon(\bar{U}(K)-\underline{U}(K))} x_{j}}{|\bar{U}(K)-\underline{U}(K)|}
$$

Step 3: Assign each object to the lower approximation $\underline{U}(\mathrm{~K})$ or upper approximation $\underline{U}(K)$ of cluster i cluster respectively. For each object vector $\mathrm{x}$, let $\mathrm{d}\left(\mathrm{x}, \mathrm{c}_{\mathrm{j}}\right)$ is the distance between itself and the centroid of cluster $c_{j}$. Let $d(x, c j)$ is min $1 \leq j \leq K d(x, c j)$. The ratio $d(x$, $\left.\mathrm{c}_{\mathrm{i}}\right) / \mathrm{d}\left(\mathrm{x}, \mathrm{c}_{\mathrm{j}}\right), \quad 1 \leq \mathrm{i}, \mathrm{j} \leq \mathrm{K}$ is used to determine the membership of $x$ as follows:

Step 4: Repeat Steps 2 and 3 until convergence.

\section{EXPERIMENTAL RESULTS}

In this paper, the image samples are taken from the benchmark MIAS database analyzing for analyzing the proposed method. 14 Haralick features were extracted using Gray level Cooccurrence Matrix (GLCM). The sub-matrices of size $5 \times 5$ is used for constructing GLCM at different angle with distance $\mathrm{d}=$ 1 and then feature are extracted. Further feature are clustered into five groups by RKM algorithm, each groups is partition into one segment, the segmented image show in Figure 3. The same features are used to cluster using K- Means and FCM algorithms with five groups each groups is partition into one segment, the segmented image shown in Figure 4 and Figure 5. The quality of segmentation result are measured using MSE and RMSE if the error value becomes low means that the better results. Figure2 shows the proposed system.

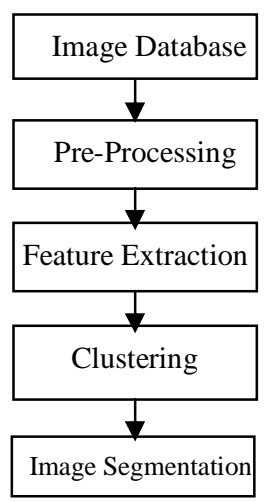

Figure2. Proposed system
The MSE and RMSE values for the RKM segmentation, FCM segmentation and K-Means segmentation are tabulated in table I, table II, table III, table IV, table V and table VI respectively. According to the segmentation errors means square error (MSE) and root mean square error (RMSE) the GLCM at distance 1 and angle 450 gives the best result for all tested image. These are demonstrated in Figure 5.

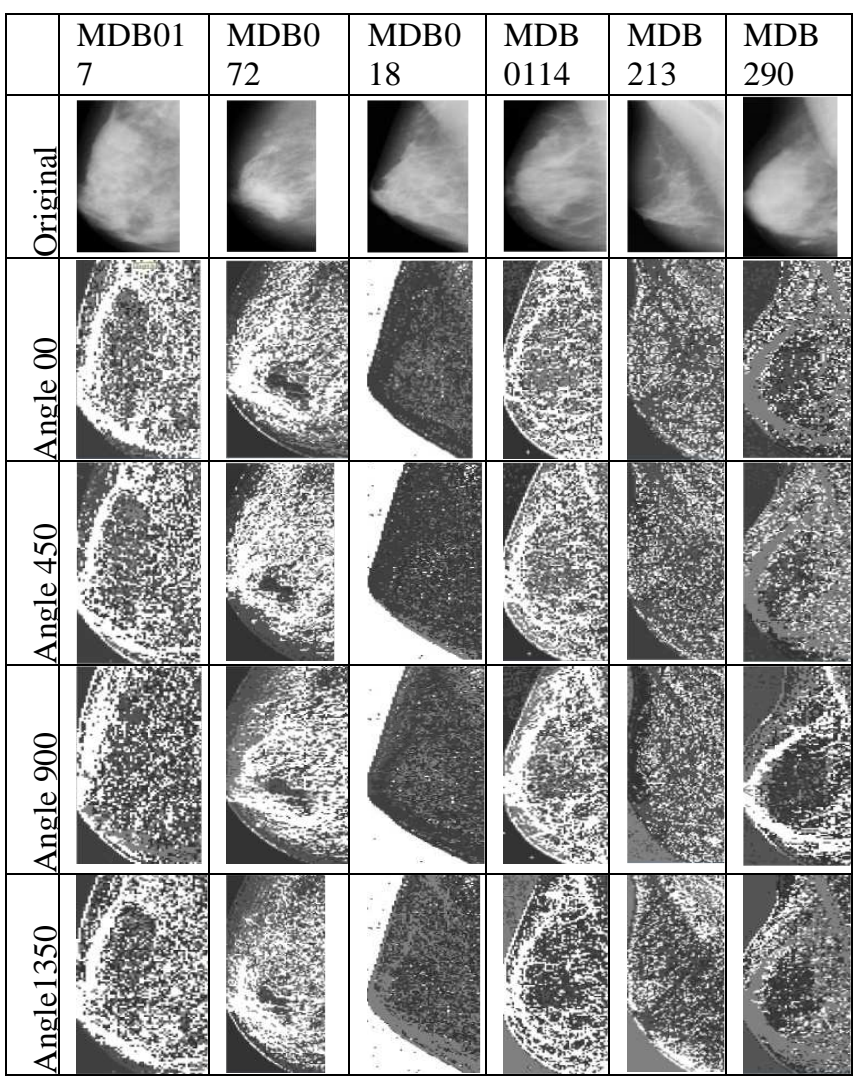

Figure3. Segmented Results in Rough K-Means Algorithm

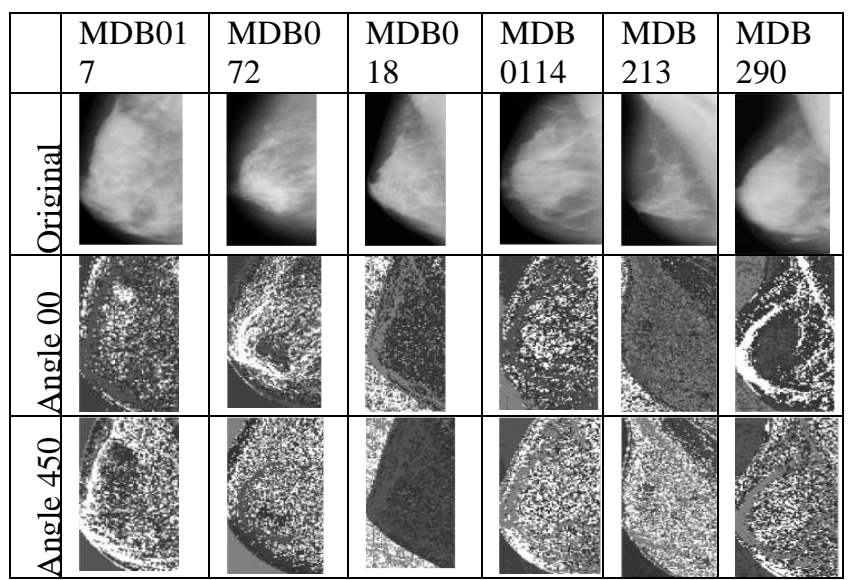




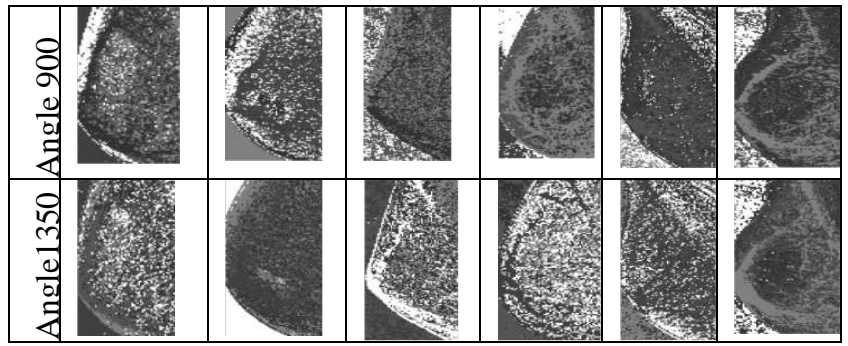

Figure4. Segmented Results in Fuzzy C-Means Algorithm

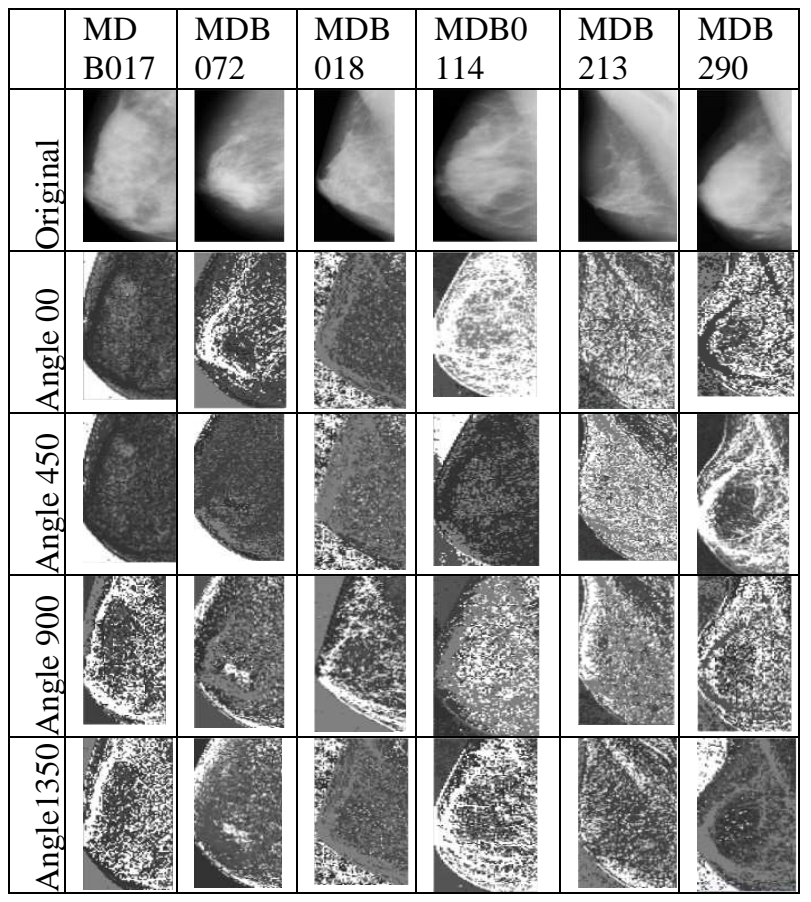

Figure5. Segmented Results in K-Means Algorithm

Performance Analysis on RKM segmentation in-order to error rate (MSE)

\begin{tabular}{|l|l|l|l|l|l|l|}
\hline \multirow{2}{*}{$\begin{array}{l}\text { Sample } \\
\text { Image }\end{array}$} & \multicolumn{2}{|l|}{ MSE } \\
\cline { 2 - 7 } & $\begin{array}{l}\text { mdb0 } \\
17\end{array}$ & mdb0 & mdb0 & $\begin{array}{l}\text { mdb1 } \\
18\end{array}$ & $\begin{array}{l}\text { mdb2 } \\
14\end{array}$ & $\begin{array}{l}\text { mdb29 } \\
0\end{array}$ \\
\hline Angle & $9.75 \mathrm{e}+$ & $7.65 \mathrm{e}+$ & $6.27 \mathrm{e}$ & $8.23 \mathrm{e}$ & $5.63 \mathrm{e}$ & $7.38 \mathrm{e}+$ \\
00 & 003 & 003 & +003 & +003 & +003 & 003 \\
\hline Angle & $8.05 \mathrm{e}+$ & $9.17 \mathrm{e}+$ & $6.34 \mathrm{e}$ & $8.26 \mathrm{e}$ & $5.77 \mathrm{e}$ & $7.31 \mathrm{e}+$ \\
450 & 003 & 003 & +003 & +003 & +003 & 003 \\
\hline Angle & $9.82 \mathrm{e}+$ & $8.09 \mathrm{e}+$ & $6.02 \mathrm{e}$ & $8.06 \mathrm{e}$ & $5.79 \mathrm{e}$ & $8.06 \mathrm{e}+$ \\
900 & 003 & 003 & +003 & +003 & +003 & 003 \\
\hline Angle & $9.11 \mathrm{e}+$ & $7.15 \mathrm{e}+$ & $5.74 \mathrm{e}$ & $1.10 \mathrm{e}$ & $6.18 \mathrm{e}$ & $6.91 \mathrm{e}+$ \\
1350 & 003 & 003 & +003 & +004 & +003 & 003 \\
\hline
\end{tabular}

Performance Analysis on RKM segmentation in-order to error rate (RMSE)

\begin{tabular}{|l|l|l|l|l|l|l|}
\hline Sample & \multicolumn{2}{l}{ RMSE } & \multicolumn{6}{|l|}{} \\
\cline { 2 - 7 } & $\begin{array}{l}\text { mdb0 } \\
17\end{array}$ & $\begin{array}{l}\text { mdb07 } \\
2\end{array}$ & $\begin{array}{l}\text { mdb0 } \\
18\end{array}$ & $\begin{array}{l}\text { mdb1 } \\
14\end{array}$ & $\begin{array}{l}\text { mdb2 } \\
13\end{array}$ & $\begin{array}{l}\text { mdb29 } \\
0\end{array}$ \\
\hline $\begin{array}{l}\text { Angle } \\
\text { 00 }\end{array}$ & 98.76 & 87.51 & 79.19 & 90.73 & 75.04 & 85.91 \\
\hline $\begin{array}{l}\text { Angle } \\
450\end{array}$ & 89.17 & 95.77 & 79.63 & 90.91 & 75.97 & 85.54 \\
\hline $\begin{array}{l}\text { Angle } \\
900\end{array}$ & 99.15 & 89.97 & 77.60 & 92.75 & 76.13 & 89.79 \\
\hline $\begin{array}{l}\text { Angle } \\
1350\end{array}$ & $\begin{array}{l}100.9 \\
1\end{array}$ & 84.59 & 75.77 & $\begin{array}{l}104.9 \\
6\end{array}$ & 78.65 & 83.13 \\
\hline
\end{tabular}

Performance Analysis on FCM segmentation in-order to error rate (MSE)

\begin{tabular}{|c|c|c|c|c|c|c|}
\hline \multirow[b]{2}{*}{$\begin{array}{l}\text { Sa } \\
\mathrm{mpl} \\
\mathrm{e} \\
\text { Ima } \\
\text { ge }\end{array}$} & \multicolumn{6}{|l|}{ MSE } \\
\hline & $\begin{array}{l}\text { mdb0 } \\
17\end{array}$ & $\begin{array}{l}\text { mdb0 } \\
72\end{array}$ & $\begin{array}{l}\mathrm{mdb} 0 \\
18\end{array}$ & $\begin{array}{l}\text { mdb11 } \\
4\end{array}$ & $\begin{array}{l}\text { mdb2 } \\
13\end{array}$ & $\begin{array}{l}\text { mdb2 } \\
90\end{array}$ \\
\hline $\begin{array}{l}\text { An } \\
\text { gle } \\
00\end{array}$ & $\begin{array}{l}1.08 \mathrm{e}+ \\
004\end{array}$ & $\begin{array}{l}1.18 \mathrm{e}+ \\
004\end{array}$ & $\begin{array}{l}1.41 \mathrm{e}+ \\
004\end{array}$ & $\begin{array}{l}8.77 \mathrm{e}+ \\
003\end{array}$ & $\begin{array}{l}8.84 \mathrm{e} \\
+003\end{array}$ & $\begin{array}{l}1.10 \mathrm{e} \\
+004\end{array}$ \\
\hline $\begin{array}{l}\text { An } \\
\text { gle } \\
450\end{array}$ & $\begin{array}{l}8.11 \mathrm{e}+ \\
003\end{array}$ & $\begin{array}{l}1.06 \mathrm{e}+ \\
004\end{array}$ & $\begin{array}{l}1.01 \mathrm{e}+ \\
004\end{array}$ & $\begin{array}{l}8.41 \mathrm{e}+ \\
003\end{array}$ & $\begin{array}{l}7.94 \mathrm{e} \\
+003\end{array}$ & $\begin{array}{l}9.43 \mathrm{e} \\
+003\end{array}$ \\
\hline $\begin{array}{l}\text { An } \\
\text { gle } \\
900 \\
\end{array}$ & $\begin{array}{l}1.11 \mathrm{e}+ \\
004\end{array}$ & $\begin{array}{l}1.30 \mathrm{e}+ \\
004\end{array}$ & $\begin{array}{l}1.19 \mathrm{e}+ \\
004\end{array}$ & $\begin{array}{l}9.97 \mathrm{e}+ \\
003\end{array}$ & $\begin{array}{l}9.86 \mathrm{e} \\
+003\end{array}$ & $\begin{array}{l}1.07 \mathrm{e} \\
+004\end{array}$ \\
\hline $\begin{array}{l}\text { An } \\
\text { gle } \\
135 \\
0\end{array}$ & $\begin{array}{l}1.16 e+ \\
004\end{array}$ & $\begin{array}{l}1.29 \mathrm{e}+ \\
004\end{array}$ & $\begin{array}{l}1.10 \mathrm{e}+ \\
004\end{array}$ & $\begin{array}{l}1.17 \mathrm{e}+ \\
004\end{array}$ & $\begin{array}{l}1.01 \mathrm{e} \\
+004\end{array}$ & $\begin{array}{l}1.09 \mathrm{e} \\
+004\end{array}$ \\
\hline
\end{tabular}

Performance Analysis on FCM segmentation in-order to error rate (RMSE)

\begin{tabular}{|l|l|l|l|l|l|l|}
\hline Sa & \multicolumn{2}{l|}{ RMSE } & \multicolumn{5}{l|}{} \\
\cline { 2 - 7 } $\begin{array}{l}\text { e } \\
\text { Ima } \\
\text { ge }\end{array}$ & $\begin{array}{l}\text { mdb0 } \\
17\end{array}$ & $\begin{array}{l}\text { mdb0 } \\
72\end{array}$ & $\begin{array}{l}\text { mdb0 } \\
18\end{array}$ & $\begin{array}{l}\text { mdb11 } \\
4\end{array}$ & $\begin{array}{l}\text { mdb2 } \\
13\end{array}$ & $\begin{array}{l}\text { mdb2 } \\
90\end{array}$ \\
\hline $\begin{array}{l}\text { An } \\
\text { gle } \\
\text { 00 }\end{array}$ & 104.17 & 109.00 & 118.99 & 93.68 & 94.05 & $\begin{array}{l}105.9 \\
9\end{array}$ \\
\hline $\begin{array}{l}\text { An } \\
\text { gle } \\
\text { 450 }\end{array}$ & 90.08 & 102.99 & 100.92 & 91.75 & 89.10 & 97.11 \\
\hline $\begin{array}{l}\text { An } \\
\text { gle } \\
900\end{array}$ & 105.78 & 114.08 & 109.20 & 99.89 & 99.31 & 103.7 \\
\hline $\begin{array}{l}\text { An } \\
\text { gle } \\
135\end{array}$ & 107.83 & 113.58 & 105.20 & 108.32 & 100.6 & 104.6 \\
0 & & & & & 1 & 6 \\
\hline
\end{tabular}


Performance Analysis on K-Means segmentation in-order to error rate (MSE)

\begin{tabular}{|c|c|c|c|c|c|c|}
\hline \multirow{2}{*}{$\begin{array}{l}\text { Sa } \\
\mathrm{mpl} \\
\mathrm{e} \\
\text { Ima } \\
\text { ge }\end{array}$} & \multicolumn{6}{|l|}{ MSE } \\
\hline & $\begin{array}{l}\text { mdb0 } \\
17\end{array}$ & $\begin{array}{l}\text { mdb0 } \\
72\end{array}$ & $\begin{array}{l}\mathrm{mdb} 0 \\
18\end{array}$ & $\begin{array}{l}\text { mdb11 } \\
4\end{array}$ & $\begin{array}{l}\text { mdb2 } \\
13\end{array}$ & $\begin{array}{l}\text { mdb2 } \\
90\end{array}$ \\
\hline $\begin{array}{l}\text { An } \\
\text { gle } \\
00\end{array}$ & $\begin{array}{l}1.24 \mathrm{e}+ \\
004\end{array}$ & $\begin{array}{l}1.61 \mathrm{e}+ \\
004\end{array}$ & $\begin{array}{l}1.56 \mathrm{e}+ \\
004\end{array}$ & $\begin{array}{l}1.31 \mathrm{e}+ \\
004\end{array}$ & $\begin{array}{l}1.15 \mathrm{e} \\
+004\end{array}$ & $\begin{array}{l}1.18 \mathrm{e} \\
+004\end{array}$ \\
\hline $\begin{array}{l}\text { An } \\
\text { gle } \\
450\end{array}$ & $\begin{array}{l}1.18 \mathrm{e}+ \\
004\end{array}$ & $\begin{array}{l}1.24 \mathrm{e}+ \\
004\end{array}$ & $\begin{array}{l}1.20 \mathrm{e}+ \\
004\end{array}$ & $\begin{array}{l}1.05 \mathrm{e}+ \\
004\end{array}$ & $\begin{array}{l}1.03 \mathrm{e} \\
+004\end{array}$ & $\begin{array}{l}1.08 \mathrm{e} \\
+004\end{array}$ \\
\hline $\begin{array}{l}\text { An } \\
\text { gle } \\
900\end{array}$ & $\begin{array}{l}1.19 \mathrm{e}+ \\
004\end{array}$ & $\begin{array}{l}1.82 \mathrm{e}+ \\
004\end{array}$ & $\begin{array}{l}1.27 \mathrm{e}+ \\
004\end{array}$ & $\begin{array}{l}1.07 \mathrm{e}+ \\
004\end{array}$ & $\begin{array}{l}1.06 \mathrm{e} \\
+004\end{array}$ & $\begin{array}{l}1.18 \mathrm{e} \\
+004\end{array}$ \\
\hline $\begin{array}{l}\text { An } \\
\text { gle } \\
135 \\
0\end{array}$ & $\begin{array}{l}1.25 \mathrm{e}+ \\
004\end{array}$ & $\begin{array}{l}1.86 \mathrm{e}+ \\
004\end{array}$ & $\begin{array}{l}1.24 \mathrm{e}+ \\
004\end{array}$ & $\begin{array}{l}1.28 \mathrm{e}+ \\
004\end{array}$ & $\begin{array}{l}1.15 \mathrm{e} \\
+004\end{array}$ & $\begin{array}{l}1.24 \mathrm{e} \\
+004\end{array}$ \\
\hline
\end{tabular}

Performance Analysis on K-Means segmentation in-order to error rate (RMSE)

\begin{tabular}{|c|c|c|c|c|c|c|}
\hline \multirow{2}{*}{$\begin{array}{l}\text { Sa } \\
\text { mpl } \\
\text { e } \\
\text { Ima } \\
\text { ge }\end{array}$} & \multicolumn{6}{|l|}{ RMSE } \\
\hline & $\begin{array}{l}\text { mdb0 } \\
17\end{array}$ & $\begin{array}{l}\text { mdb0 } \\
72\end{array}$ & $\begin{array}{l}\mathrm{mdb} 0 \\
18\end{array}$ & $\begin{array}{l}\text { mdb11 } \\
4\end{array}$ & $\begin{array}{l}\text { mdb2 } \\
13\end{array}$ & $\begin{array}{l}\text { mdb2 } \\
90\end{array}$ \\
\hline $\begin{array}{l}\text { An } \\
\text { gle } \\
00\end{array}$ & 111.61 & 127.26 & 119.82 & 114.64 & $\begin{array}{l}107.2 \\
7\end{array}$ & $\begin{array}{l}108.9 \\
1\end{array}$ \\
\hline $\begin{array}{l}\text { An } \\
\text { gle } \\
450\end{array}$ & 108.97 & 111.41 & 109.81 & 102.23 & $\begin{array}{l}101.8 \\
5\end{array}$ & $\begin{array}{l}104.2 \\
6\end{array}$ \\
\hline $\begin{array}{l}\text { An } \\
\text { gle } \\
900\end{array}$ & 109.34 & 135.16 & 112.85 & 103.77 & $\begin{array}{l}103.2 \\
9\end{array}$ & $\begin{array}{l}108.9 \\
3\end{array}$ \\
\hline $\begin{array}{l}\text { An } \\
\text { gle } \\
135 \\
0\end{array}$ & 111.99 & 136.69 & 111.66 & 113.55 & $\begin{array}{l}107.3 \\
8\end{array}$ & $\begin{array}{l}111.5 \\
8\end{array}$ \\
\hline
\end{tabular}

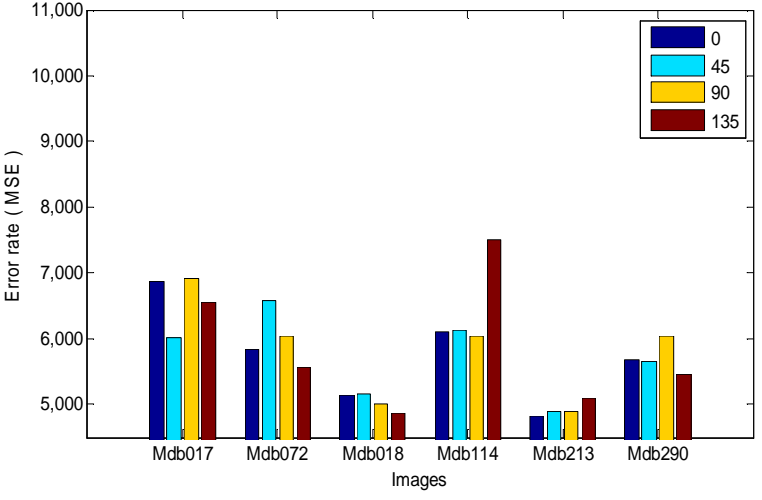

(a)

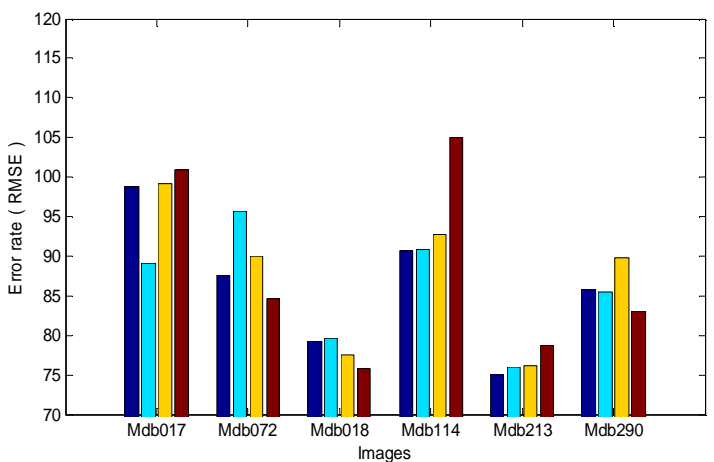

(b)

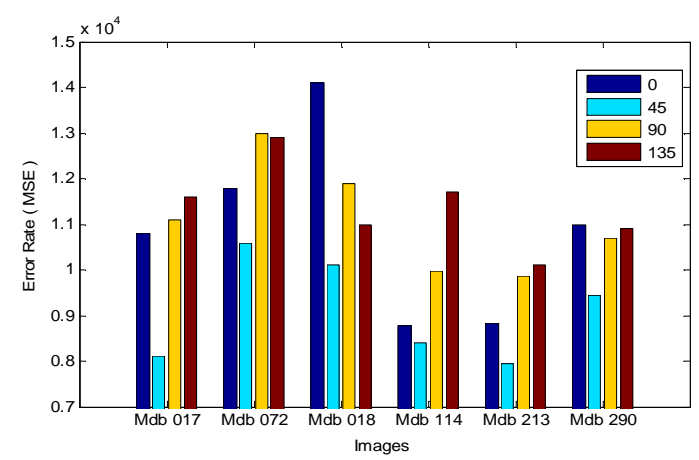

(c)

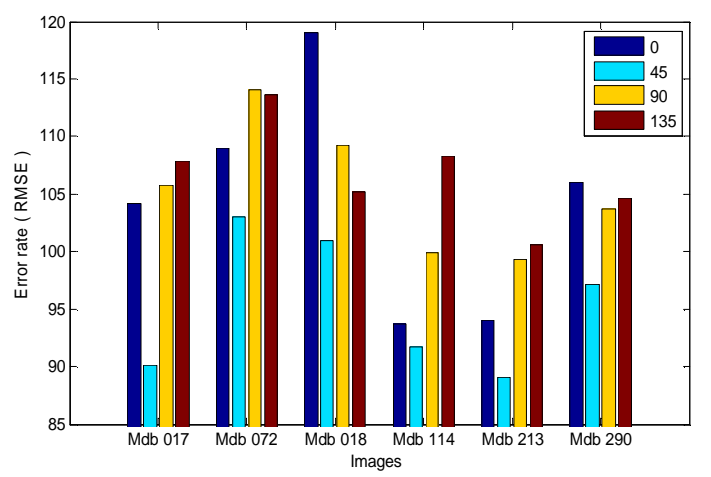

(d) 


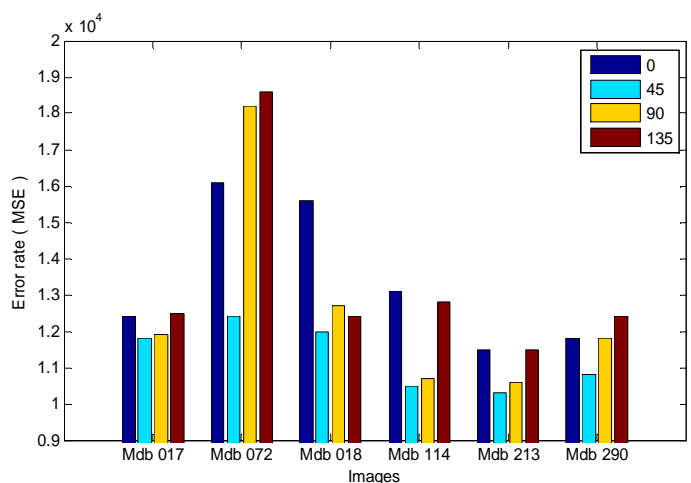

(e)

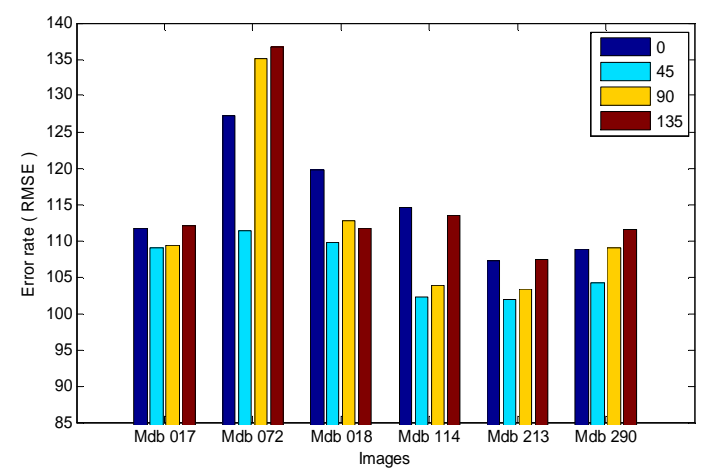

(f)

Figure6. Performance Analysis on Error rates in (a) MSE (b) RMSE RKM algorithm (c) MSE (d) RMSE FCM Algorithm, (e) MSE (f) RMSE K-Means Algorithm

\section{CONCLUSIONS}

In this paper, Rough K-Means algorithm (RKM) is proposed for mammogram image segmentation. The 14 Haralick features are extracted from mammogram image using Gray Level Cooccurrence Matrix (GLCM) for different angles. The features are clustered by K-Means, Fuzzy C-Means (FCM) and RKM algorithms inorder to segment the region of interests for further classification. The performance of the RKM segmentation is evaluated using MSE and RMSE measures. The proposed segmentation algorithm is compared with K-Means algorithm and FCM algorithm. It was observed that RKM segmentation algorithm out performs the benchmark K-Means algorithm and FCM algorithm. Further the resultant mammogram can be used for the detection of abnormalities in human breast like calcification, circumscribed lesions etc. This is the direction for further research.

\section{ACKNOWLEDGMENTS}

The second author immensely acknowledges the UGC, New Delhi for partial financial assistance under UGC-SAP (DRS) Grant No. F.3-50/2011
The first and third authors immensely acknowledge the partial financial assistance under University Research Fellowship, Periyar University, Salem

\section{REFERENCES}

[1] M. Vasantha et. al. "Medical Image Feature, Extraction, Selection and Classification" International Journal of Engineering Science and Technology Vol. 2(6), 2010, 2071-2076

[2] Trivedi M. M, Bezdek J. C, Low-level segmentation of aerial images with fuzzy clustering, IEEE Trans.on Systems, Man and Cybernetics, Volume 16, Issue 4 July, 1986.

[3] Sanmeet Bawa, A thesis on "Edge Based Region Growing", Department of Electronics and communication Engimeering, Thapar Institute of Engineering \& Technology (Deemed University), India, June 2006.

[4] Aswini Kumar Mohanty, Swapnasikta Beberta, Saroj Kumar Lenka "Classifying Benign and Malignant Mass using GLCM and GLRLM based Texture Features from Mammogram". International Journal of Engineering Research and Applications (IJERA). Vol. 1, Issue 3, pp.687-693. ISSN: 2248-9622

[5] Jain, A.K., Murty M.N., and Flynn P.J. (1999): Data Clustering: A Review, ACM Computing Surveys, Vol 31, No. 3, 264-323.

[6] Madhu Yedla, Srinivasa Rao Pathakota, T M Srinivasa , "Enhancing K-Means Clustering Algorithm with Improved Initial Center" , International Journal of Computer Science and Information Technologies, Vol. 1 (2), pp121-125, 2010

[7] Z. Pawlak. Rough Sets. Theoretical Aspects of Reasoning About Data. Kluwer, The Netherlands, 1991.

[8] L. Polkowski. Rough Sets. Mathematical Foundations. Physica-Verlag, Heidelberg, 2003.

[9] Z. Wojcik. Rough approximation of shapes in pattern recognition. Computer Vision, Graphics, and Image Processing, 40:228-249, 1987.

[10] S.K. Pal, B. U. Pal, and P. Mitra. Granular computing, rough entropy and object extraction.Pattern Recognition Letters, 26(16):2509-2517, 2005.

[11] Moti Melloul and Leo Joskowicz, Segmentation of microcalcification in X-ray mammograms using entropy thresholding, CARS 2002, pp. 49-56 (2002).

[12] S. Kobashi, K. Kondo, and Y. Hata. Rough sets based medical image segmentation with connectedness. In 5th Int. Forum on Multimedia and Image Processing, pages 197-202, 2004.

[13] J.F. Peters and M. Borkowski. K-means indiscernibility relation over pixels. In Int. Conference on Rough Sets and Current Trends in Computing, pages 580-585, 2004.

[14] C-B. Chena and L-Y. Wang. Rough set-based clustering with refinement using shannon's entropy theory. 
Computers and Mathematics with Applications, 52(1011):1563-1576, 2006.

[15] Mohabey and A.K. Ray. Fusion of rough set theoretic approximations and FCM for color image segmentation. In IEEE Int. Conference on Systems, Man, and Cybernetics, volume 2,pages 1529-1534, 2000.

[16] S. Widz, K. Revett, and 'Sle zak D. Application of rough set based dynamic parameter optimization to mri segmentation. In 23rd Int. Conference of the North American Fuzzy Information Processing Society, pages 440-445, 2004.

[17] R.C. Gonzalez, R.E. Woods, "Digital Image processing", Pretice Hall. 2007.

[18] Boss, R. Subash Chandra, K. Thangavel, and D. Arul Pon Daniel. "Mammogram image segmentation using fuzzy clustering." In Pattern Recognition, Informatics and Medical Engineering (PRIME), 2012 International Conference on, pp. 290-295. IEEE, 2012.

[19] K. Bovis and S. Singh. Detection of masses in mammograms using texture features. 15th International Conference on Pattern Recognition (ICPR'00), 2:2267, 2000.

[20] R. Marti, R. Zwiggelaar, and C. Rubin. A novel similarity measure to evaluate image correspondence. 15th International Conference on Pattern Recognition (ICPR'00), 3:3171, 2000.

[21] L. Blot and R. Zwiggelaar. Extracting background texture in mammographic images: Co-occurrence matrices based approach. Proceedings of the 5th International Workshop on Digital Mammography, Toronto (Canada), pages 142-148, 2000.

[22] L. Blot, R. Zwiggelaar, and C.R.M. Boggis. Enhancement of abnormal structures in mammographic images. Proceedings of Medical Image Understanding and Analysis, pages 125-128, 2000.

[23] L. Blot and R. Zwiggelaar. Background texture extraction for the classification of mammographic parenchymal patterns. Medical Image Understanding and Analysis, pages 145-148, 2001.

[24] N. Youssry, F.E.Z. Abou-Chadi, and A.M. El-Sayad. Early detection of masses in digitized mammograms using texture features and neuro-fuzzy model. 4th Annual IEEE Conf on Information Technology Applications in Biomedicine, 2003.

[25] J. Marti, J. Freixenet, X. Mu noz, and A. Oliver. Active region segmentation of mammographic masses based on texture, contour and shape features. Springer-Verlag Berlin Heidelberg, LNCS 2652:478-485, 2003.

[26] M. Jirari. A computer aided detection system for digital mammograms based on radial basis functions and feature extraction techniques. IEEE Engineering in Medicine and Biology 27th Annual Conference, 2005.

[27] L. Costaridou, P.N. Sakellaropoulos, M.A. Kristalli, S.G. Skiadopoulos, A.N. arahaliou, I.S. Boniatis, and G.S. Panayiotakis. Multi resolution feature analysis for differentiation of breast masses from normal tissue. 1st
International Conference on Experiments/Process/ System Modelling /Simulation/Optimization, 2005.

[28] Karahaliou, I. Boniatis, P. Sakellaropoulos, S. Skiadopoulos, G. Panayiotakis, and L. Costaridou. Can texture of tissue surrounding micro calcifications in mammography be used for breast cancer diagnosis. Nuclear Instruments and Methods in Physics Research A 580, pages 1071-1074, 2007.

[29] M. Lyra, S. Lyra, B. Kostakis, S. Drosos, and C. Georgosopoulos. Digital mammography texture analysis by computer assisted image processing. IEEE International Workshop on Imaging Chania Greece September 2, pages 223-227, 2008.

[30] Karahaliou, I. Boniatis, G. Skiadopoulos, F. Sakellaropoulos, N. Arikidis, E. A. Likaki, G. Panayiotakis, and L. Costaridou. Breast cancer diagnosis: Analyzing texture of tissue surrounding micro calcifications. IEEE Transactions on information technology in Biomedicine, 12:6, 2008.

[31] R. Beichel and M. Sonka. Computer vision approaches to medical image analysis. Lecture Notes in Computer Science, Springer, 4241, 2006.

[32] R.M Haralick and K. Shanmugam. Textural features for image classification. IEEE Transactions on Systems, Man, and Cybernetics SMC-3 (6), 6:610-621, 1973.

\section{BIOGRAPHIES}

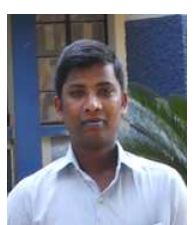

Subash Chandra Boss Rajaraman was born in 1985 at Villuppuram District, Tamilnadu, India. He is received the Master of Science in Computer Science in 2009 from Pondicherry University, Pondicherry, India. He obtained his M.Phil (Computer Science) Degree from Periyar University, Salem, Tamilnadu, India in 2010. Currently he is doing fulltime Ph.D., Periyar University, Salem, Tamilnadu, India. His area of interests includes Medical Image Processing, Data Mining, Neural Network, Fuzzy logic, and Rough Set.

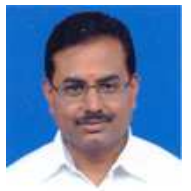

Thangavel Kuttiyannan was born in 1964 at Namakkal, Tamilnadu, India. He received his Master of Science from the Department of Mathematics, Bharathidasan University in 1986, and Master of Computer Applications Degree from Madurai Kamaraj University, India in 2001. He obtained his Ph.D. Degree from the Department of Mathematics, Gandhigram Rural Institute-Deemed University, Gandhigram, India in 1999. Currently he is working as Professor and Head, Department of Computer Science, Periyar University, Salem. He is a recipient of Tamilnadu Scientist award for the year 2009 and Sir C.V.Raman award for the year 2013. His area of interests includes Medical Image Processing, Data Mining, Artificial Intelligence, Neural Network, Fuzzy logic, and Rough Set. 


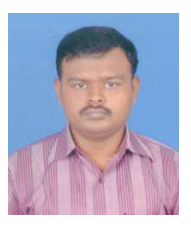

Arul Pon Daniel Thiyoder was born at Tuticorin District, Tamil Nadu, India, in 1986. $\mathrm{He}$ received the Master of Computer Applications degree from the Bharathidasan University, Tiruchirapally, TN, India, and Master of Business Administrations in Human Resource degree from the Periyar University, Salem, TN, India, in 2009. He is currently pursuing the Ph.D. degree with the Department of Computer Science, Periyar University, Salem, $\mathrm{TN}$, India. His research interests include data mining, image processing, array processing, signal processing and artificial intelligence. 